\title{
Novos táxons em Onciderini (Coleoptera, Cerambycidae, Lamiinae)
}

\author{
Ubirajara R. Martins ${ }^{1,3}$ \& Maria Helena M. Galileo ${ }^{2,3}$
}

${ }^{1}$ Museu de Zoologia, Universidade de São Paulo. Caixa Postal 42494, 04218-970 São Paulo-SP, Brasil. urmsouza@usp.br ${ }^{2}$ Museu de Ciências Naturais, Fundação Zoobotânica do Rio Grande do Sul. Caixa Postal 1188, 90001-970 Porto Alegre-RS, Brasil. galileo@fzb.rs.gov.br ${ }^{3}$ Pesquisador do CNPq.

\begin{abstract}
New taxa in Onciderini (Coleoptera, Cerambycidae, Lamiinae). New taxa described: Oncideres sparsemaculatus sp. nov., from Guatemala (San Marcos); Oncideres estebani sp. nov. from Costa Rica (Alajuela); Neohylus alexandrei sp. nov. and Hypsioma bahiensis, sp. nov. from Brazil (Rondônia and Bahia, respectively); Paraplerodia gen. nov., type species, P. acarinata sp. nov., Hesycha biguttata sp. nov., Trestonia lateapicata sp. nov. and Pseudobeta transversa sp. nov. from Bolívia (Santa Cruz).
\end{abstract}

KEYWORDS. Hesycha; Neohylus; Oncideres; Paraplerodia gen. nov.; Pseudobeta; Trestonia.

RESUMO. Novos táxons descritos: Oncideres sparsemaculatus sp. nov., da Guatemala (San Marcos); Oncideres estebani sp. nov. da Costa Rica (Alajuela); Neohylus alexandrei sp. nov. e Hypsioma bahiensis, sp. nov. do Brasil (Rondônia e Bahia, respectivamente); Paraplerodia gen. nov., espécie-tipo, P. acarinata sp. nov., Hesycha biguttata sp. nov., Trestonia lateapicata sp. nov. e Pseudobeta transversa sp. nov. da Bolívia (Santa Cruz).

PALAVRAS-CHAVE. Hesycha; Neohylus; Oncideres; Paraplerodia gen. nov.; Pseudobeta; Trestonia.

A tribo Onciderini tem sido objeto de inúmeras contribuições por diversos autores, como citado em Martins \& Galileo (2007: 127), após a monografia de Dillon \& Dillon $(1945,1946)$. Neste trabalho publicam-se novos táxons das Américas Central e do Sul.

As siglas utilizadas no texto correspondem a: INIA, Instituto Nacional de Investigación y Tecnología Agraria y Alimentaria, Madrid, Espanha; MIUC, Museo de Insectos, Universidad de Costa Rica, San José; MNKM, Museo Noel Kempff Mercado, Santa Cruz, Bolívia; MZSP, Museu de Zoologia, Universidade de São Paulo, São Paulo, Brasil; UEFS, Museu de Zoologia, Universidade Estadual de Feira de Santana, Bahia, Brasil; USNM, National Museum of Natural History, Washington, Estados Unidos.

\section{Oncideres sparsemaculatus sp. nov.} (Fig. 1)

Etimologia. Latim, sparsus $=$ esparso; maculatus $=$ manchado.

Macho. Tegumento preto. Cabeça coberta por pubescência alaranjada, mais concentrada ao redor dos olhos e em duas faixas longitudinais nos lados da fronte. Lobos oculares inferiores tão longos quanto às genas. Escapo densamente rugoso, principalmente, no lado interno, menos no ápice. Antenômeros III a XI cobertos por pubescência alaranjada com os ápices escurecidos. Antenômero XI com o dobro do comprimento do $\mathrm{X}$ e curvo no ápice.

Espinholateral do protórax bem desenvolvido.Pronoto com cinco máculas glabras; as laterais pouco indicadas. Escutelo com pubescência escassa. Mesepimeros e metepisternos com pubescência castanha, esparsa. Mesosterno e centro do metasterno com pubescência alaranjada e esbranquiçada.

Élitros alaranjados na declividade basal e ao redor das inúmeras manchas pequenas de pubescência branca; região central ocupada por larga faixa de pubescência branca pouco contrastante; grânulos basais distantes, mais concentrados na região umeral; restante da superfície elitral com máculas glabras.

Fêmures e tíbias cobertos por pubescência alaranjada. Profêmures rugosos no lado externo. Urosternitos com pubescência predominantemente alaranjada.

Dimensões em mm, holótipo macho. Comprimento total, 23,1; comprimento do protórax, 3,5; maior largura do protórax, 6,3; comprimento do élitro, 16,7; largura umeral, 8,4 .

Material-tipo. Holótipo macho, GUATEMALA, San Marcos: San Marcos ("Rd. from Fraternidad to Bojonal"), 6-7.VII.2005, R. E. Woodruff \& J. Monzon col., " light $1600 \mathrm{~m}$ cloud forest” (USNM).

Discussão. Oncideres sparsemaculatus sp. nov. assemelha-se a O. albipilosa Noguera, 1993 descrita de Campeche e de Yucatan, México. Difere pelo escapo (macho) sem sulcos transversais na base, mas densamente irregular; pelo tubérculo lateral do protórax mais desenvolvido; pela faixa transversal de pubescência branca no meio dos élitros pouco aparente e densamente entremeada por pubescência alaranjada; pelos metepisternos com pubescência castanha. Em O. albipilosa, o escapo tem três sulcos profundos e transversais na base; o tubérculo lateral do protórax é pouco desenvolvido (examinado a fotografia do parátipo macho, Bezark 2008); a faixa transversal de pubescência branca no meio dos élitros é aparente e não está entremeada por pubescência alaranjada; os metepisternos têm pubescência parda, ocre e esbranquiçada. 


\section{Oncideres estebani sp. nov.}

(Fig. 2)

Etimologia. Epíteto em homenagem ao coletor da espécie, José Esteban Durán do INIA.

Macho. Tegumento preto. Lados da cabeça cobertos por pubescência alaranjada, mais concentrada ao redor dos olhos. Fronte com pubescência escassa, mais densa em linhas paralelas nos lados. Lobos oculares inferiores pouco mais longos que as genas. Vértice com pubescência alaranjada. Antenas atingem a extremidade dos élitros no meio do antenômero VII. Escapo com pubescência alaranjada e sulcos transversais da base até um pouco antes do meio. Antenômero XI com o dobro do comprimento do $\mathrm{X}$, levemente curvo no ápice.

Protórax revestido por pubescência castanho-alaranjada; lados com rugas; tubérculo lateral moderadamente projetado. Pronoto com fileira central, transversal, de cinco manchas glabras; duas pequenas manchas de pubescência alaranjada mais concentrada no lado do meio. Mesosterno e centro do metasterno com pubescência amarelada. Lados do metasterno com pubescência castanha entremeada por pubescência amarelada. Mesepimeros, metepimeros e metepisternos com pubescência castanha.

Élitros com pubescência castanho-alaranjada nos terços basal e apical; entre essas duas regiões, faixa larga transversal de pubescência branca que atinge a margem e aproxima-se da sutura; algumas máculas pequenas, esparsas, de pubescência branca no terço apical. Região basal dos élitros com tubérculos esparsos; restante da superfície com numerosas máculas glabras.

Pernas revestidas por pubescência castanho-alaranjada. Procoxas com tubérculo rugoso. Profêmures com rugas transversais no lado externo. Urosternitos com pubescência alaranjada concentrada nas orlas.

Fêmea. Antenas atingem a extremidades dos élitros no ápice do antenômero VIII. Escapo e procoxa sem rugosidades. Lados do protórax com rugas menos evidentes.

Dimensões em mm, holótipo macho/parátipo fêmea. Comprimento total, 21,7/15,9; comprimento do protórax, 3,4/2,2; maior largura do protórax, 6,2/4,8; comprimento do élitro, 16,1/12,5; largura umeral, 8,4/6,6.

Material-tipo. Holótipo macho, CosTA RicA, Alajuela: Reserva Biológica A. M. Brenes ( 840 m), 22.III.2007, José Esteban col., armadilha luminosa (400+2x125W, HG)" (MIUC). Parátipos: mesmos dados do holótipo, 1 macho (MZSP), 1 fêmea (INIA).

Discussão. Oncideres estebani $\mathbf{s p}$. nov. assemelha-se a O. pittieri Gahan, 1894, também conhecida da Costa Rica, e que apresenta máculas fulvas nos élitros, pubescência fulva na cabeça e no pronoto, mancha branca dos élitros estendida lateralmente do quarto basal ao terço apical e, no dorso, distante da sutura; a base dos élitros tem grânulos próximos e o terço apical com manchas de pubescência fulva (sem manchas de pubescência branca). Em $O$. estebani $\mathbf{s p .}$ nov. a pubescência geral é predominantemente castanhoalaranjada; a faixa branca no meio dos élitros é transversal e não se expande anterior e posteriormente junto à margem e, no dorso, aproxima-se da sutura; o terço apical tem algumas manchas pequenas de pubescência branca e os grânulos da base dos élitros são esparsos.

\section{Neohylus alexandrei sp. nov.}

(Fig. 3)

Etimologia. O nome da espécie é dado em homenagem a Alexandre de Almeida e Silva, Universidade Federal de Rondônia, que nos enviou importante material de Rondônia para identificação e permitiu que os holótipos ficassem depositados no MZSP.

Macho. Tegumento castanho-escuro, menos nos 2/3 basais dos tarsômeros V, alaranjados. Cabeça revestida por pubescência acastanhada, exceto na fronte e nas genas onde a pubescência é escassa. Lobos oculares inferiores muito desenvolvidos com o triplo do cumprimento das genas. Tubérculos anteníferos projetados e acuminados. Antenas ultrapassam o ápice dos élitros com quatro artículos. Escapo escassamente pubescente; rugoso, acentuadamente, no lado interno da metade basal. Antenômero III unicolor, preto. Antenômeros IV-IX com anel amarelado na base; (X e XI faltam).

Protórax tronco-cônico revestido por pubescência castanho-clara. Pronoto com cinco tubérculos glabros. Esternos torácicos revestidos por pubescência castanhoclara nos lados e mais esbranquiçada no meio. Escutelo com pubescência esparsa, acastanhada.

Élitros revestidos por pubescência castanho-clara com algumas áreas de pubescência castanho-escura; metade basal dotada de grânulos organizados em fileiras longitudinais no dorso.

Procoxas com tubérculo unciforme. Fêmures com pubescência esparsa em toda a superfície e anel apical de pubescência densa amarelada. Metatíbias engrossadas; no lado externo com depressão alongada. Urosternitos com pubescência castanho-clara nos lados e acastanhada no meio.

Dimensões em mm, holótipo macho. Comprimento total, 19,8; comprimento do protórax, 3,1; maior largura do protórax, 4,9; comprimento do élitro, 14,2; largura umeral, 8,4.

Material-tipo. Holótipo macho, BRASIL, Rondônia: Jaci-Paraná (Rio Madeira, margem direita), 17.I.2004 (sem coletor), luminosa 932 (MZSP).

Discussão. O gênero Neohylus Monné, 2005 contém única espécie, N. dubius (Dillon \& Dillon, 1945), examinado através de única fêmea cujas pernas estavam faltando ( l.c.:105). O macho ora descrito apresenta: procoxas com tubérculo curvo; metatíbias engrossadas; tarsômeros $\mathrm{V}$ alaranjados nas bases. Neohylus alexandrei sp. nov. separa-se de $N$. dubius pelo número menor de pontos na metade basal dos élitros e pela ausência de faixa oblíqua de pubescência fulva nos élitros.

\section{Hesycha biguttata sp. nov.}

(Fig. 4)

Etimologia. Latim, guttatus $=$ maculado com pequenas manchas parecendo gotas, alusivo às duas manchas brancas dos élitros. 
Macho. Tegumento castanho-escuro ou preto. Cabeça revestida por pubescência castanho-clara. Lobos oculares inferiores tão longos quanto às genas. Escapo gradualmente engrossado para o ápice. Antenômero III com pubescência acastanhada, indistintamente mais esbranquiçada num anel basal; IV com os dois terços apicais castanhos e terço basal com pubescência branca; V-VII com anel basal branco; VIII e IX, com a metade basal branca; X e XI quase inteiramente brancos.

Protórax coberto por pubescência castanho-amarelada esparsa. Pronoto sem tubérculos.

Élitros revestidos por pubescência amarelada com grande mancha de pubescência acastanhada no meio dos lados; pequena mancha de pubescência branca dorsal, no limite posterior da área acastanhada; metade apical com pubescência amarelada amplamente mesclada de pubescência acastanhada. Úmeros com pequeno tubérculo.

Face ventral com pubescência predominantemente esbranquiçada, mesclada por pubescência castanha.

Dimensões em mm, holótipo macho. Comprimento total 10,8; comprimento do protórax, 2,0; maior largura do protórax, 2,5; comprimento do élitro, 8,0; largura umeral, 4,3.

Material-tipo. Holótipo macho, BolíviA, Santa Cruz: Buena Vista, XI.2004, R. Clarke col. (MNKM).

Discussão. Duas espécies do gênero Hesycha Fairmaire \& Germain, 1859 têm uma pequena mancha dorsal próxima do meio dos élitros: H. bimaculata, Martins \& Galileo, 1990 e H. simplex Martins \& Galileo, 1990, ambas ocorrem na Mata Atlântica. Hesycha biguttata sp. nov. também tem essa mancha branca nos élitros, mas distingue-se de $\mathrm{H}$. bimaculata Martins \& Galileo, 1990 pelos lobos oculares inferiores tão longos quanto as genas e de H.simplex pelo antenômero III com anel basal estreito e o IV com o terço basal cobertos por pubescência branca. Em H. bimaculata os lobos oculares inferiores mais curtos do que as genas; em H.simplex os antenômeros III e IV têm tegumento unicolor e castanhoescuro.

\section{Paraplerodia gen. nov.}

\section{Espécie-tipo. Paraplerodia acarinata sp. nov.}

Fronte alongada. Lobos oculares inferiores $(1,4 \mathrm{~mm})$ apenas mais curtas que as genas $(1,2)$. Lobos oculares superiores com seis fileiras de omatídios; tão afastados entre si quanto o dobro da largura de um lobo. Tubérculos anteníferos distantes entre si, cônicos. Escapo sem cicatriz; gradualmente alargado até a clava; atinge o meio do protórax. Antenas (macho) atingem o ápice dos élitros. Antenômero III reto.

Protórax tronco-cônico, sem tubérculo lateral. Pronoto com gibosidade discreta, a cada lado do meio; sem rugas.

Élitros sem crista centro-basal e com pontuação simples. Úmeros arredondados não seguidos por carenas.

Procoxas sem tubérculos unciformes, Meso- e metatíbias ligeiramente engrossadas para o ápice sem depressão no lado externo. Tarsômeros $\mathrm{V}$ com tegumento unicolor.
Discussão. Paraplerodia gen. nov., aproxima-se de Proplerodia Martins \& Galileo, 1990 e Tibiosioma Martins \& Galileo, 1990, pelo antenômero III reto, pontuação elitral simples, fronte alongada e úmeros projetados. Distinguese de ambos pelos úmeros sem carena após o tubérculo e pelas metatíbias dos machos não engrossadas. Separa-se de Proplerodia pelas antenas mais curtas, pelo escapo que atinge o meio do protórax e pelas procoxas sem tubérculo unciforme. Em Proplerodia as antenas atingem a ponta dos élitros na extremidade do antenômero VII, o escapo alcança a borda posterior do protórax e as procoxas apresentam tubérculo. Difere de Tibiosioma, pelos úmeros fortemente projetados e não prolongados por carena e pela fronte alongada. Em Tibiosioma a fronte é subquadrada e os úmeros são seguidos por carena.

\section{Paraplerodia acarinata sp. nov.} (Fig. 5)

Etimologia. Grego, $a=$ não; carinatus $=$ carenado, alusivo à ausência de carena após o úmero.

Macho. Tegumento de maneira geral castanho-escuro. Cabeça revestida por pubescência amarelo-alaranjada com pontuação indistinta na fronte. Escapo com pubescência esparsa. Antenômero III com pubescência esbranquiçada na base e gradualmente acastanhada para o ápice; antenômeros IV, VI, VIII e X com os dois terços basais revestidos por pubescência esbranquiçada e terço apical acastanhado; antenômeros V, VII e IX com os anéis esbranquiçados basais muito estreitos.

Protórax coberto por pubescência amarelada, mais adensada nos lados da base e no centro. Esternos torácicos revestidos por pubescência amarelada.

Élitros com úmeros arredondados e salientes, cobertos por pubescência castanha, entremeada por escassas máculas de pubescência branca, principalmente, nos lados do meio.

Fêmures revestidos por pubescência acastanhada e esbranquiçada na base. Urosternitos revestidos por pubescência amarelada e, a cada lado, com pequena mancha de pubescência alaranjada.

Dimensões em mm, holótipo macho. Comprimento total 16,5; comprimento do protórax, 2,3; maior largura do protórax, 4,3; comprimento do élitro, 12,6; largura umeral, 7,2 .

Material-tipo. Holótipo macho, BolíviA, Santa Cruz: Buena Vista, (Hotel Fauna \& Flora, 4-6 km SSE Buena Vista, 17²9'95”S, 633' 15”'W, 400-500m) 3-14.XI.2003, S. W. Lingafelter col., "black light" (MNKM).

\section{Trestonia lateapicata sp. nov.} (Fig. 6)

Etimologia. Latim, latus = largo; apicatus = apical; alusivo à mancha preta apical dos élitros, larga.

Macho. Tegumento castanho-avermelhado. Cabeça revestida por pubescência alaranjada concentrada atrás dos 
olhos e nos tubérculos anteníferos. Fronte com pubescência alaranjada esparsa, mais concentrada nos lados e em duas pequenas manchas transversais no meio. Vértice com duas faixas paralelas de pubescência castanha. Lobos oculares inferiores mais longos que as genas. Antenas atingem o ápice dos élitros na ponta do antenômero VII. Escapo com pubescência alaranjada na metade basal e pubescência menos concentrada na clava. Antenômeros III-VI com a metade basal coberta por pubescência esbranquiçada e a metade apical preta.

Pronoto com área larga central longitudinal de pubescência alaranjada com intromissão de pubescência branca na região basal; faixas longitudinais, a cada lado, de pubescência preta e alaranjada. Partes laterais do protórax e esternos torácicos com pubescência esbranquiçada.

Élitros com os dois terços anteriores cobertos por pubescência esbranquiçada, pouco mais concentrada posteriormente e, no terço apical, faixa preta, irregular, que envolve manchas irregulares de pubescência alaranjada. Úmeros levemente projetados.

Pernas com pubescência alaranjada, mais concentrada na metade dorsal dos fêmures. Protíbias com pubescência alaranjada e escurecida no terço apical. Meso- e metatíbias alaranjadas com anel anteapical preto. Urosternitos I-IV com pubescência esbranquiçada, esparsa. Urosternito V com pubescência alaranjada nos lados.

Dimensões em mm, holótipo macho. Comprimento total, 8,4 ; comprimento do protórax, 1,5 ; maior largura do protórax, 1,9; comprimento do élitro, 5,9; largura umeral, 2,6.

Material-tipo. Holótipo macho, BOLÍVIA, Santa Cruz: Potrerillos

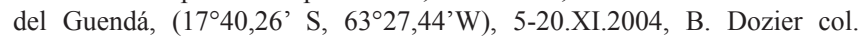
(MNKM).

Discussão. Trestonia lateapicata sp. nov. assemelha-se a T. frontalis (Erichson, 1847) pelo aspecto da mancha apical dos élitros. Difere pela fronte revestida por pubescência alaranjada esparsa; pelos urosternitos apicais com pubescência esbranquiçada esparsa. Em T. frontalis a fronte e os três últimos urosternitos são cobertos por pubescência branca, densa.

\section{Hypsioma bahiensis sp. nov.} (Fig. 7)

Etimologia. Latim, bahiensis $=$ procedente da Bahia.

Fêmea. Tegumento preto. Cabeça revestida por pubescência branca, densa na área genal, atrás dos olhos e no vértice exceto na sutura coronal; fronte com pubescência branca intercalada por áreas de pubescência alaranjada que constitui faixa a cada lado prolongada até o ápice dos tubérculos anteníferos. Pontos grossos e esparsos na fronte. Tubérculos anteníferos projetados. Antenas não atingem o ápice elitral. Escapo revestido por pubescência brancoacinzentada e alaranjada no dorso com anel castanho anteapical. Antenômeros III com pubescência esbranquiçada exceto no ápice, preto; IV- XI castanho-avermelhados revestidos por pubescência branco-acinzentada com terço apical preto.

Lados do protórax com pubescência branco-acinzentada uniforme; pronoto com essa pubescência intercalada por pequenas manchas de pubescência alaranjada e acastanhada e pontos glabros. Pronoto com tubérculo longitudinal a cada lado. Esternos torácicos predominantemente revestidos por pubescência branco-acinzentada, mais densa nos mese- e metepimeros, base dos metepisternos e centro do metasterno.

Élitros com pubescência esbranquiçada variegada de alaranjada e máculas castanhas; pubescência esbranquiçada: declividade basal, sutura até o meio, faixa transversal, descontínua, no meio e manchas irregulares no terço apical; manchas castanhas mais concentradas na região posterior a faixa transversal esbranquiçada. Crista centro-basal com pontos tuberculados na orla anterior.

Pernas revestidas por pubescência esbranquiçada, mais adensada nos fêmures. Fêmures com anel apical preto. Urosternitos cobertos por pubescência branco-acinzentada com áreas levemente acastanhadas no meio da base dos urosternitos III e IV e no centro da metade apical do urosternito $\mathrm{V}$.

Dimensões em $\mathrm{mm}$, holótipo fêmea. Comprimento total 21,0; comprimento do protórax, 3,4; maior largura do protórax (base), 5,5; comprimento do élitro, 15,8; largura umeral, 8,9.

Material-tipo. Holótipo fêmea, Brasil, Bahia: São Félix do Coribe

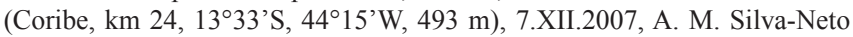
col. (UEFS 36394).

Discussão. Hypsioma bahiensis sp. nov. pertence ao grupo de espécies com o urosternito I pubescente. Pelo pronoto com duas gibosidades a cada lado assemelha-se a $H$. robusta Dillon \& Dillon, 1945. Difere principalmente pelo colorido dos élitros com faixa transversal, irregular, de pubescência branca.

\section{Pseudobeta transversa sp. nov.} (Fig. 8)

Etimologia, Latim, transversus, alusivo à faixa acastanhada dos élitros.

Macho. Tegumento acastanhado. Cabeça revestida por pubescência branca nas genas e atrás dos olhos e castanhoamarelada na fronte e no vértice. Lobos oculares inferiores tão longos quanto às genas. Antenas atingem as pontas dos élitros na ponta do antenômero IX. Escapo clavado com terço basal recoberto por pubescência esbranquiçada e dois terços apicais revestidos por pubescência acastanhada. Flagelômeros com terço basal amarelado e restante acastanhado. Antenômero III bissinuoso.

Protórax com lados subparalelos com duas depressões, uma próxima da orla anterior e outras perto do meio; com pubescência castanho-amarelada e faixa longitudinal de pubescência esbranquiçada. Pronoto com pubescência castanho-amarelada e o terço posterior com pubescência esbranquiçada intercalada por pubescência amarelada. 


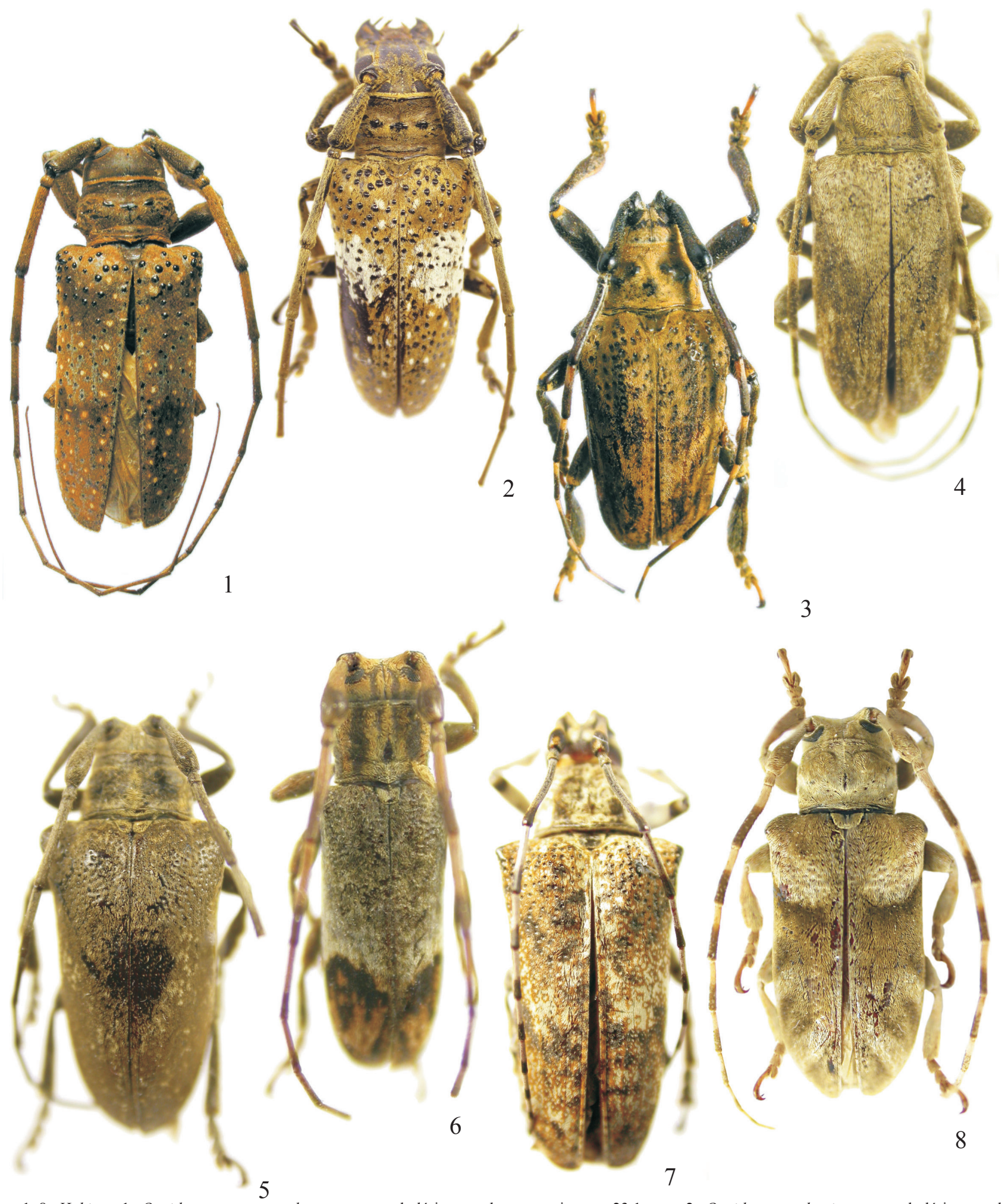

Figs. 1-8. Habitus. 1. Oncideres sparsemaculatus sp. nov., holótipo macho, comprimento $23,1 \mathrm{~mm}$; 2. Oncideres estebani sp. nov., holótipo macho, comprimento 21,7 mm; 3. Neohylus alexandrei $\mathbf{s p . ~ n o v . , ~ h o l o ́ t i p o ~ m a c h o , ~ c o m p r i m e n t o ~ 1 9 , 8 ~ m m ; ~ 4 . ~ H e s y c h a ~ b i g u t t a t a ~ s p . ~ n o v . , ~ h o l o ́ t i p o ~ m a c h o , ~ c o m p r i m e n t o ~}$ $10,8 \mathrm{~mm}$; 5. Paraplerodia acarinata sp. nov., holótipo macho, comprimento $16,5 \mathrm{~mm}$; 6 . Trestonia lateapicata sp. nov., holótipo macho, comprimento 8,4 $\mathrm{mm}$; 7. Hypsioma bahiensis, sp. nov., holótipo fêmea, comprimento 21,0 mm; 8. Pseudobeta transversa sp. nov., holótipo macho, comprimento $12,8 \mathrm{~mm}$.

Escutelo coberto por pubescência esbranquiçada.

Élitros com pubescência castanho-amarelada e faixas de pubescência esbranquiçada: uma no terço basal que não envolve os úmeros; uma mancha arredondada, lateral, atrás do meio; uma faixa oblíqua em sentido ascendente da sutura para a margem no terço apical; uma faixa de pubescência castanho-escuro atrás da mancha esbranquiçada basal e mancha castanha, menos contrastante no terço apical. 
Pontos simples e esparsos no dorso da metade basal. Mesoe metafêmures com as bases pubescentes de castanhoalaranjado e o restante castanho-escuro. Esternos torácicos revestidos por pubescência esbranquiçada e restante da face ventral revestida por pubescência castanho-amarelada,

Dimensões em mm, holótipo macho. Comprimento total, 12,8; comprimento do protórax, 2,2; maior largura do protórax, 3,2; comprimento do élitro, 9,5; largura umeral, 5,2 .

Material-tipo. Holótipo macho, Bolivia, Santa Cruz, Buena Vista (Hotel Flora \& Fauna, 5 km SSE, 17²9'98”S, 63³9'13”W, 440 m), 8.II.2004, R. Clarke col., "black + white lights" (MNKM).

Discussão. Pseudobeta transversa sp. nov. distingue-se das demais espécies do gênero por apresentar faixa castanha, transversal, no quarto basal dos élitros. Em P. doris (Thomson, 1868) e em $P$. seabrai Monné \& Fragoso, 1984 os élitros têm faixas oblíquas escuras; em P. ferruginea Galileo \& Martins, 1990 os élitros são variegados de alaranjado e castanho.
Agradecimentos. Aos curadores das coleções que nos enviaram material para estudo: Alexandre de Almeida e Silva, Universidade Federal de Rondônia, Porto Velho; Freddy Bravo (UEFS); James Wappes (American Coleoptera Museum e USNM); José Esteban Duran (INIA); Robin Clarke, Hotel Fauna \& Flora, Buena Vista. A Eleandro Moysés (BIC/CNPq), Museu de Ciências Naturais, Fundação Zoobotânica do Rio Grande do Sul. Porto Alegre, pelas fotografias e tratamento das imagens.

\section{REFERENCIAS}

Bezark, L. G. 2008. A Photographic Catalog of the Cerambycidae of the New World. http://plant.cdfa.ca.gov

Dillon, L. S. \& E. S. Dillon. 1945. The tribe Onciderini Part I. Scientific Publications of the Reading Public Museum 5: 1-186.

Dillon, L. S. \& E. S. Dillon. 1946. The tribe Onciderini Part II. Scientific Publications of the Reading Public Museum 6: 189-413.

Martins, U. R. \& M. H. M. Galileo. 2007. Novas espécies de Onciderini (Coleoptera, Cerambycidae, Lamiinae) da Bolívia. Papéis Avulsos de Zoologia 48: 27-31. 